\title{
A Análise Contextual de Tarefas no Desenvolvimento de Fluxo de Informações
}

\author{
Andre Zanki Cordenonsi ${ }^{1}$, Giliane Bernardi ${ }^{2}$, Eliandro dos Santos Costa $^{1}$ \\ ${ }^{1}$ Departamento de Documentação - Universidade Federal de Santa Maria (UFSM) \\ Av. Roraima n. 1000 - 97.105-900 - Santa Maria - RS - Brasil \\ 22Área de Ciências Naturais e Tecnológicas - Centro Universitário Franciscano \\ (UNIFRA) \\ Rua dos Andradas n. 1614 - 97.010-032 - Santa Maria - RS - Brasil
}

\begin{abstract}
Resumo: Este artigo apresenta uma proposta da utilização da Análise Contextual de Tarefas para o desenvolvimento de fluxo de informações dentro de sistemas computacionais. Esta técnica pode ser utilizada no auxílio ao levantamento de requisitos de um software, colaborando na reorganização das tarefas cotidianas dos usuários, de tal forma a eliminar vícios administrativos antes da implementação do sistema de informação. É apresentado um estudo de caso em um sistema real, onde o fluxo de informação desenvolvido e o fluxo desejado pelos usuários apresenta discordâncias importantes.
\end{abstract}

\begin{abstract}
This paper presents the Contextual Task Analysis used to develop an information flow control. This technique can be use to aid the requirements software approach and it is useful to rearrange the end-users task. The Contextual Task Analysis can eliminate administrative gaps before software implementation. A case study in a real system is present, showing significant differences between the information flow developed and the user desired flows.
\end{abstract}

\section{Introdução}

Ergonomia, usabilidade e interação-humano computador (IHC) são termos cada vez mais comuns dentro do processo de desenvolvimento de software. Ao centrar a definição do funcionamento de sistemas computacionais sob a ótica do usuário, é possível diminuir o vácuo tecnológico e ontológico entre as diferentes visões de um sistema. É comum verificar que a Engenharia de Software (Pressman, 2006) trata o desenvolvimento de sistemas de informação sob os seus aspectos funcionais, ou seja, como a aplicação deve funcionar e em quais passos os problemas precisam ser resolvidos. Por outro lado, os pesquisadores e usuários da IHC lidam com as interações do componente humano com a máquina, definindo a interface dos usuários.

Em (Cybys et al, 2005), é possível perceber que a independência do diálogo utilizada neste tipo de arquitetura (aplicação e interface podem ser desenvolvidos e evoluídos separadamente) tem gerado situações que induzem ao isolamento do diálogo, onde, tipicamente, a aplicação é desenvolvida prioritariamente e, após, a interface é inserida como uma casca que engloba os aspectos funcionais e, muitas vezes, mascara os problemas de projeto. 
Neste artigo, está sendo proposto a utilização e comparação de uma técnica de levantamento de requisitos utilizado pela ergonomia, conhecida como Análise Contextual de Tarefas, que tem como principal vantagem unir os aspectos internos do funcionamento da aplicação com a interface que o usuário espera para o software que está sendo desenvolvido. Na próxima seção será apresentada uma breve descrição da técnica e, posteriormente, um estudo de caso é discutido através de um modelo real implementado na Universidade Federal de Santa Maria.

\section{Análise Contextual de Tarefas}

A Análise Contextual de Tarefas é uma técnica de investigação da Interação HumanoComputador. Conceitualmente, a técnica estuda situações existentes, realizando uma análise desde o início do ciclo de desenvolvimento, quando se faz a identificação dos requisitos, permitindo saber quem vai usar a interface e o quê irá fazer nela. Ela é considerada uma ferramenta colaborativa e acessória para a identificação de requisitos de um sistema. Usualmente, esta técnica descreve os passos que um usuário faz para completar uma tarefa e, em alguns casos, como ele realiza estas tarefas.

É possível abordar esta teoria no desenvolvimento de sistemas de informação, aplicando a análise para obter os requisitos de uma aplicação. Os requisitos de software são declarações que definem como um produto deve desempenhar ou o que ele deve fazer. Em relação aos usuários, os seus requisitos são declarações, em linguagem natural e/ou diagramas, sobre as funções que o sistema deve fornecer e as restrições sob as quais deve operar (Sommervile, 2003). Eles são criados a partir do entendimento das necessidades do usuário que, deste modo, podem ser justificados e relacionados aos dados. É nesse nicho que a Análise Contextual de Tarefa pode ser melhor explorada.

A diferença entre a Análise de Sistemas Tradicional e a Análise Contextual de Tarefa pode ser visualizada na tabela 01 .

\begin{tabular}{|c|c|c|}
\hline & Análise de Sistemas Tradicional & Análise Contextual de Tarefa \\
\hline Metas & $\begin{array}{l}\text { Entradas para o design de processo de } \\
\text { software e estruturas de dados }\end{array}$ & $\begin{array}{l}\text { Entradas para o design de interface do } \\
\text { usuário }\end{array}$ \\
\hline Saídas & $\begin{array}{l}\text { Modelos de funções e modelos de } \\
\text { dados }\end{array}$ & $\begin{array}{l}\text { Análises dos ambientes de trabalho, } \\
\text { análise da tarefa, cenários da tarefa, } \\
\text { modelo de organização da tarefa } \\
\text { corrente do usuário }\end{array}$ \\
\hline Impactos & Implementação da arquitetura & $\begin{array}{l}\text { Reengenharia da organização da tarefa } \\
\text { e modelos de seqüências da tarefa, } \\
\text { modelo conceitual de design, design } \\
\text { padronizados de telas e design } \\
\text { detalhado da IU }\end{array}$ \\
\hline Foco & $\begin{array}{l}\text { Limitações técnicas de processamento } \\
\text { de informação, características de } \\
\text { dados e considerações sobre a } \\
\text { implementação de arquiteturas }\end{array}$ & $\begin{array}{l}\text { Limitações do processamento humano } \\
\text { das informações, trabalho corrente e } \\
\text { modelo de trabalho corrente do } \\
\text { usuário }\end{array}$ \\
\hline $\begin{array}{l}\text { Objetos de } \\
\text { análise }\end{array}$ & Dados e funções & $\begin{array}{l}\text { Usuários, ambiente de trabalho dos } \\
\text { usuários e objetivos do trabalho do } \\
\text { usuário }\end{array}$ \\
\hline
\end{tabular}

Tabela 01: Análise de Sistemas Tradicional vs. Análise Contextual da Tarefa

Fonte: Mayhew (1999) apud HOELZEL (2004, pg. 42) 
Para realizar a análise contextual de tarefas, são reunidos usuários que tenham o mesmo perfil de navegação no sistema. Eles são instruídos a cumprir com suas tarefas diárias dentro do objetivo proposto para o sistema que está sendo desenvolvido. Para a construção dos fluxos de trabalho desenvolvidos pelos usuários, são utilizados observadores, que anotam os procedimentos realizados pelos mesmos. Além disso, é possível se utilizar de câmeras de vídeo para armazenar as informações, que podem ser revisadas quantas vezes forem necessárias.

Ao analisar o como um usuário realiza uma tarefa, a organização dos seus afazeres cotidianos é esmiuçada e, desta forma, pode-se estabelecer quais tarefas podem ser automatizadas, quais informações são relevantes para desenvolver aquela tarefa e como esta se interconecta com outras tarefas, outros sistemas computacionais ou com outros agentes humanos. A análise global da tarefa que está sendo desenvolvida, desta forma, pode ser muito mais rica em detalhes e conter informações pertinentes à implementação de um software do que a mera lista de requisitos funcionais.

Dois outros aspectos são importantes na utilização desta técnica. O primeiro deles está diretamente relacionado ao fluxo de informação. O funcionamento de um sistema de informação deve suportar a circulação de dados e informações através de procedimentos, técnicas e mecanismos usualmente designados por Tecnologias da Informação. Atualmente, os procedimentos manuais e clássicos de manipulação de informação (como livros-protocolo) estão sendo substituídos ou complementados por estas tecnologias.

A análise contextual de tarefas pode auxiliar na construção, redefinição e manutenção dos fluxos informacionais ao levar o usuário a pensar sobre seu próprio fazer. Ao construir e observar o fluxo de tarefas que ele próprio realiza, o usuário deixa de ser apenas um consultor e passa a atuar como um agente modificador da sua própria realidade que, por muitas vezes, ele desconhece nas suas nuances. Retrabalho e ineficiência são sintomas comuns de sistemas não automatizados ou semiautomatizados e tais deliberações entre usuários podem ser importantes para a readequação do seu fazer profissional antes da implementação de sistemas informatizados. É importante lembrar que a desconexão entre usuários e desenvolvedores de sistemas de informação é a causa mais comum para o fracasso na implementação de sistemas informatizados, enfatizando aqui a falta de uma ontologia básica que permita o diálogo entre as partes envolvidas, o que ocasiona a incorreta ou incompleta definição dos requisitos (Stábile, 2001).

Por outro lado, o modelo básico gerado pela Análise Contextual de Tarefas, através de um fluxo de tarefas, pode ser facilmente entendido e explicados a usuários leigos. Longe de ser um modelo completo de desenvolvimento, como a UML, o fluxo de tarefas, no entanto, apresenta sua força na simplicidade. Através de fluxos bem definidos, onde tarefas, agentes e decisões de sistema são colocadas de forma clara e transparente, os usuários sentem-se à vontade para realizar comentários ou propor correções de forma mais objetiva do que as listas intermináveis de requisitos ou os modelos orientados a objetos. Estes modelos, que podem e devem ser implementados posteriormente, são aspectos que representam a realidade mapeada para o contexto da tecnologia da informação, mas que são totalmente desprovidos de propósito para o usuário comum, que deseja apenas uma ferramenta que facilite o seu trabalho. 


\subsection{Design e Ergonomia}

Descrevendo mais detalhadamente a área envolvida da técnica de análise contextual de tarefa, para melhor contextualizar as atividades do trabalho, é possível definir o design como todo o processo de projeto de um produto ou ainda todo o projeto lógico e criativo desenvolvido para elaboração, execução e instalação de um produto.

Em Hoelzel(2004), o design é referenciado através da utilização de três tipos de conhecimentos básicos: sobre o usuário (ser humano), sobre os meios utilizados para a realização de uma tarefa (tecnologias, máquinas e métodos) e sobre o contexto sóciocultural do meio no qual o usuário vá realizar a tarefa.

Já a palavra Ergonomia deriva do grego Ergon(trabalho) e nomos(normas, regras, leis). Trata-se de uma disciplina orientada para uma abordagem sistêmica de todos os aspectos da atividade humana. Com vias de abarcar a amplitude dessa dimensão e poderem intervir nas atividades do trabalho, é preciso que os ergonomistas possuam uma abordagem holística de todo o campo de ação da disciplina, tanto em seus aspectos físicos e cognitivos, como sociais, organizacionais e ambientais. Freqüentemente esses profissionais intervêm em setores particulares da economia ou em domínios de aplicação específicos. Esses últimos caracterizam-se por sua constante mutação, com a criação de novos domínios de aplicação ou do aperfeiçoamento de outros mais antigos. Desta forma, pode-se dizer que a ergonomia é o estudo da adaptação do trabalho aos limites e capacidades do ser humano.

Dentro disso está a tarefa, cujo conceito mais simples corresponde a um trabalho prescrito. Deste modo, pode ser definida como um objetivo a atingir em determinadas condições de execução, ou seja, o que o operador tem que fazer. Para realizar as suas tarefas, o operador utiliza meios, materiais, instrumentos e/ou ferramentas que lhe são facultados para o efeito. São igualmente definidas as condições em que a tarefa deve ser realizada: um tempo, um espaço, uma ordem de operações, um envolvimento físico, normas a respeitar, entre outros.

Deste modo, a análise da tarefa centra-se no conjunto das condições de trabalho, pondo em evidência os fatores que influenciam a atividade dos trabalhadores. Assim, os elementos constituintes da tarefa são os objetivos (de produção ou de qualidade), os procedimentos (métodos de trabalho, ordens ou instruções, normas, constrangimentos temporais), os meios disponíveis (matérias, máquinas, ferramentas, documentação), o envolvimento físico (espacial, ruído, trabalho noturno) e as condições sociais do trabalho (qualificação, modalidades de remuneração, tipos de controle e sanções).

\section{Estudo de Caso: o Módulo de Protocolo e Controle de Processo}

Nesta seção, será apresentado um estudo de caso, onde foi analisado o produto final de um sistema informatizado através das técnicas usuais de levantamento de requisitos (entrevistas, questionário, observação pessoal, leitura e análise de documentos, seminários)(Rezende, 2005) e o modelo construído através da Análise Contextual de Tarefas. O sistema analisado foi o Módulo de Protocolo e Controle de Processos do SIE (Sistema de Informações para o Ensino), um software para gestão integrada para instituições de ensino superior. O módulo em questão foi desenvolvido a partir do levantamento realizado nos funcionários dos órgãos administrativos que atuavam diretamente com a documentação e suas tramitações, a partir de entrevistas realizadas por analistas de sistemas. É importante salientar que estes funcionários, na sua maioria, tem formação na área arquivística e, desta forma, possuem um vocabulário em relação à informação mais desenvolvido do que técnicos de outras áreas. 
O fluxo da figura 01 apresenta as atividades que envolvem os processos e as correspondências no Departamento de Arquivos Gerais (DAG), frisando a situação em que se encontra o ciclo de vida documental do departamento na utilização do MPCP/SIE. A descrição da figura 01 apresenta a situação atual, onde as partes em cinza são as únicas que estão implementadas através do software, desenvolvido a partir das técnicas usuais.

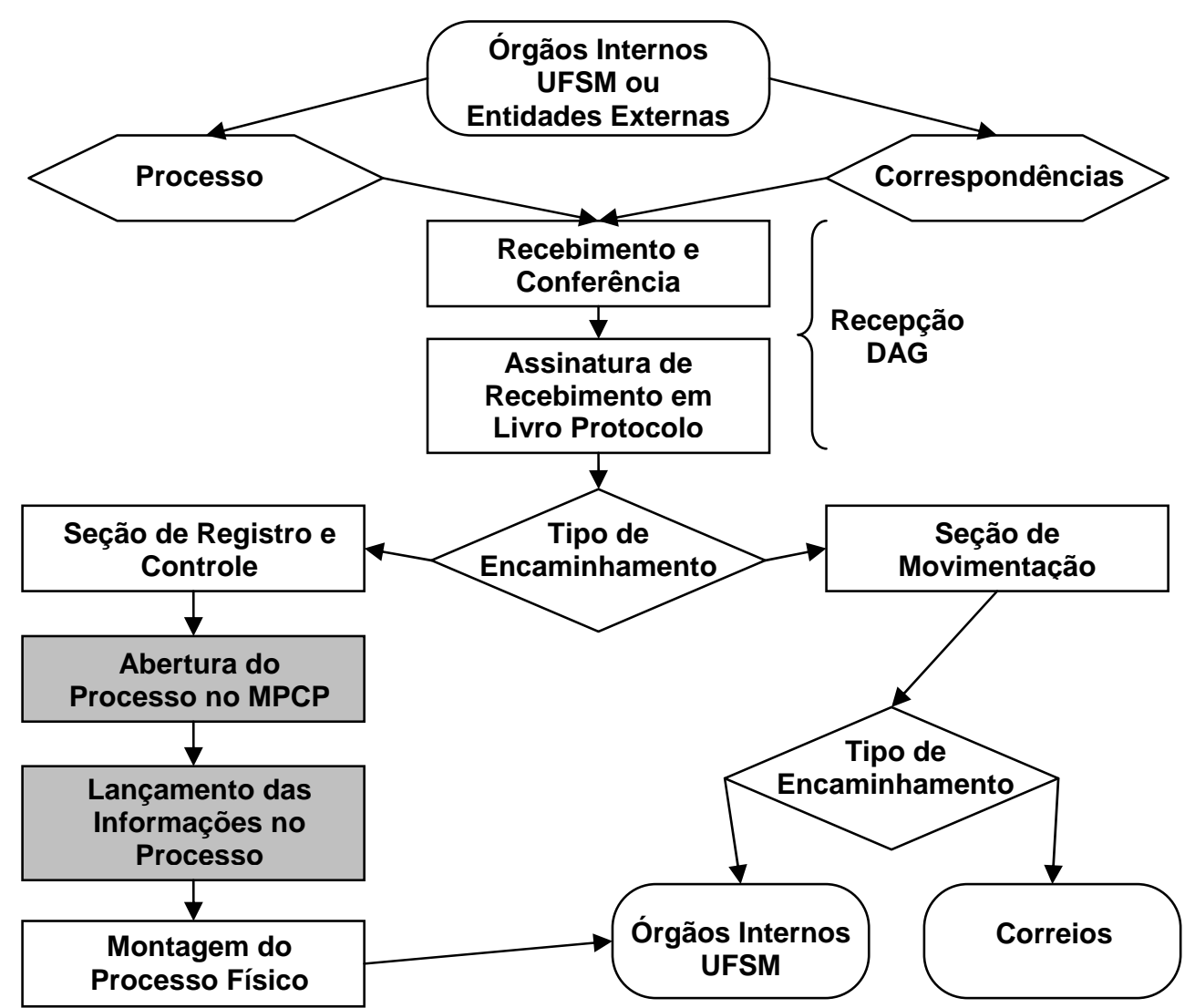

Figura 01: Fluxograma dos processos e correspondências no MPCPISIE do DAG

Como pode ser observado no fluxograma da figura 01, o DAG não tem o controle efetivo da documentação que ingressa e sai do departamento. A única parte realmente automatizada pelo sistema está destacada em cinza. Os demais processos são ignorados pelo sistema e, desta forma, a informação se esvai. Cabe, no entanto, uma explicação em relação às Correspondências. O DAG recebe dois tipos de correspondências: as que são recebidas de agentes externos e devem ser encaminhadas para os órgãos internos, e as que são recebidas dos órgãos internos e devem ser encaminhadas para os Correios.

Outro aspecto importante a ser levantando é que todos os setores ou órgãos que interagem com o DAG tem autonomia para utilizar-se do SIE, de livros-protocolo, de ambos, ou até mesmo nenhum, o que não permite um padrão ao tratamento da informação. Desta forma, muitos documentos que são processados dentro da universidade não tem nenhum tipo de registro eletrônico efetivo. 


\subsection{Análise Contextual de Tarefas}

A análise contextual de tarefas foi desenvolvida dentro do DAG, através da observação in loco dos seus afazeres, buscando compreender como as informações envolvidas no sistema analisado (correspondências e processos) eram tratadas pelos funcionários. Através destas observações, foi montado um modelo da tarefa, que foi discutido como os funcionários e é apresentado nas figuras 02 e 03. É importante observar que, durante a série de entrevistas sobre o modelo do fluxo informacional, os usuários levantaram uma série de considerações, que são reproduzidas aqui:

- Avaliam como uma falha as restrições impostas para novos tipos de tramitações ou quaisquer modificações de qualquer natureza;

- O perfil do usuário "Diretora Geral” dá acesso restrito às funções no Módulo para inclusão/alteração de informações nos processos;

- O Método de Classificação utilizado no MPCP é por Assunto, não correspondendo com o Método de Classificação Funcional utilizado no Sistema de Arquivos da Universidade;

- Falta no módulo um espaço para localização dos documentos assim como períodos para transferência, recolhimento ou eliminação dos documentos após cumprirem com o exercício de suas atividades (tabela de temporalidade);

- Falta descrever no módulo os documentos microfilmados no Laboratório de Reprografia, bem como sua situação física e condição de localização.

Consideremos as observações relatadas. A falha relacionada às restrições para novos tipos de tramitações ou modificações nas tramitações atuais é conseqüência direta, usualmente, de problemas no levantamento de requisitos. Fluxos de informações não mapeados tem, como conseqüência direta, falta de opções aos usuários do sistema. No entanto, convém salientar que a tramitação de processos é um sistema dinâmico pois, muitas vezes, a própria reforma nas instituições, principalmente públicas, acaba por alterar a forma de realizar as tarefas cotidianas. Uma solução possível, neste caso, seria a implantação do sistema através de uma ferramenta de workflow, onde os processos tivessem seu fluxo alterado de forma mais dinâmica. (Cruz, 2000).

A restrição relatada na segunda consideração retrata um caso óbvio de delegação de poderes. O perfil "Diretor Geral" do DAG deveria prover meios de alterar um processo que tenha informações digitadas equivocadamente, pois isso ocorre para os fluxos de informação no suporte papel. Ao impedir tal diretiva, o que ocorre, na prática, é o retrabalho de montar um processo novo, para que as informações sejam colocadas de forma correta, sem nenhum ganho prático real.

As três considerações seguintes retratam de forma inequívoca a falta de uma ontologia comum entre os usuários (no caso, arquivistas) e os desenvolvedores. A definição do método de classificação utilizado no sistema não seguiu as recomendações dos arquivistas, o que gera a situação insólita de arquivos em meio papel seguirem um padrão diferente de busca e filtragem do que os arquivos armazenados digitalmente. Da mesma forma, as tarefas de desenvolvimento de uma tabela de temporalidade (prazos para recolhimento, preservação, destinação e eventual destruição dos documentos), bem como a impossibilidade de referenciar documentos já microfilmados, transformam a tarefa realizada através do MPCP um tanto quanto incompleta, pois estas questões são 
tratadas da forma tradicional (através de listas em papel), pois o sistema não dá suporte ao ferramental básico do fazer arquivístico (usuário).

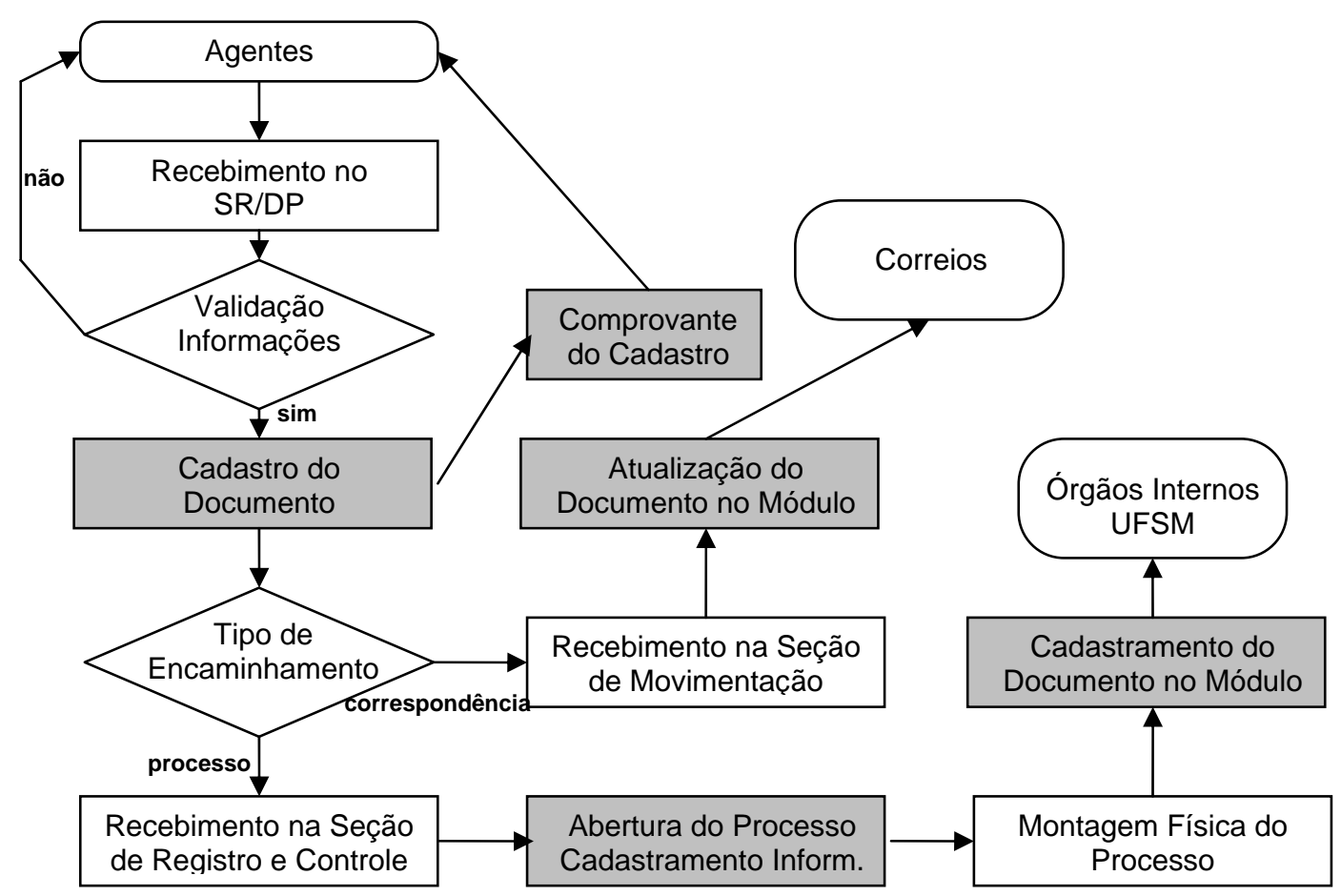

Figura 02: Análise Contextual de Tarefas para o fluxo informacional gerado pelo encaminhamento de processos e correspondências

Retomando os fluxos informacionais, é possível perceber nas figuras 02 e 03 que os processos mapeados pelos funcionários vão além da simples definição do sistema computacional. Tal fato é considerado relevante, pois os usuários foram orientados a conceber o como são realizadas as suas tarefas de uma forma completa, sem restrições. Novamente, aqui se utilizou a representação gráfica de colorir de cinza as tarefas que podem ser automatizadas por um sistema informacional. É fácil perceber que houve um aumento substancial de processos informatizados, o que não corrobora a visão de que a maioria dos usuários acredita que a informática age para obstruir e não para prestar assistência (Stábile, 2001) (Paulino, 1999) (Akers, 2007). De fato, é possível perceber que os usuários querem fazer parte da definição das ferramentas que eles utilizarão na sua vida profissional, mas muitos não sabem como fazê-lo ou tem medo de expressar suas opiniões frente aos diagramas complexos e palavreado técnico da área de desenvolvimento computacional.

Uma observação sobre a figura 03 é necessária. O DAG faz distinção entre a correspondência que sai para os órgãos da reitoria e a que vai para outros setores, pois o mesmo se encontra fisicamente junto à Reitoria. Desta forma, todos os setores do prédio onde está a reitoria retiram a correspondência diretamente no DAG, não fazendo uso do malote. Nos demais casos, o malote é utilizado e as informações sobre o número do malote e quando o mesmo foi despachado devem ser armazenadas. 


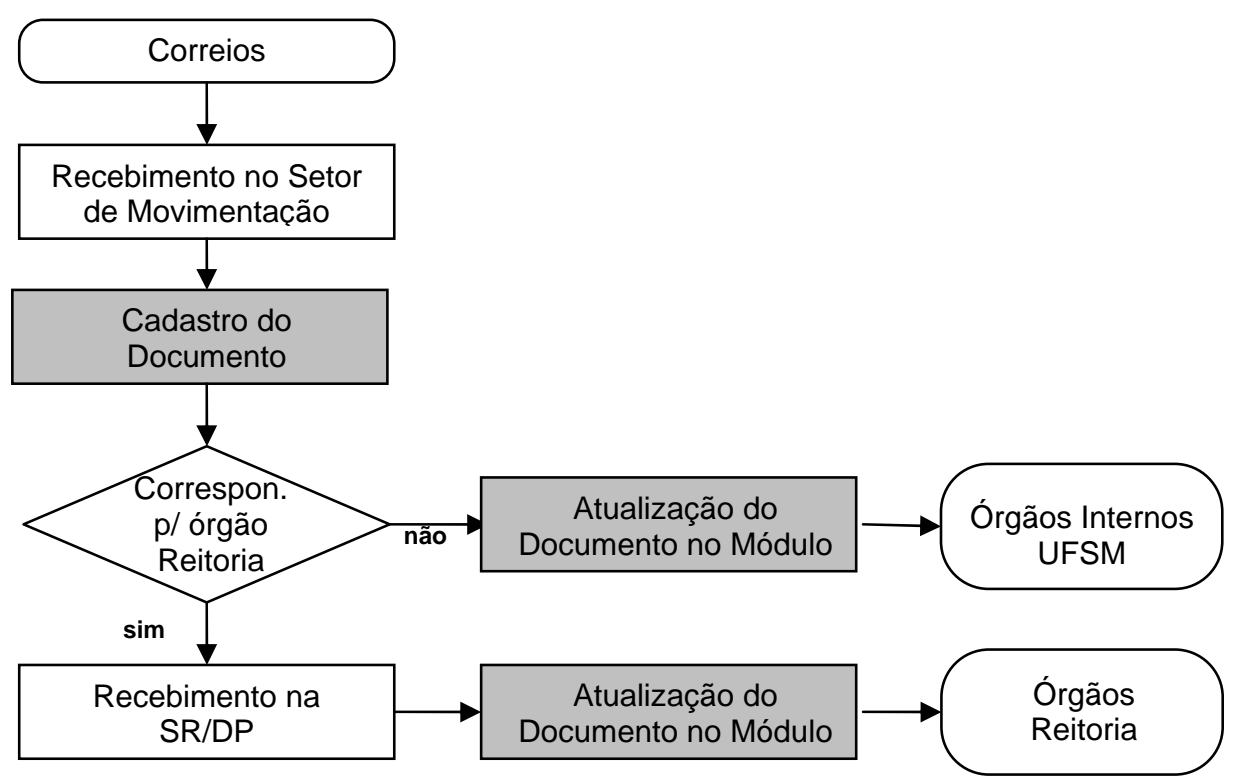

Figura 03: Análise Contextual de Tarefas para o fluxo informacional gerado pelo recebimento de correspondências

Além disso, como o SIE não trata alguns aspectos importantes do fluxo de suas atividades diárias, os funcionários do DAG desenvolveram um sistema de informação para seu próprio uso, onde é lançada grande parte da informação processada dentro do setor. Uma dessas funções é o controle à consulta, por usuários externos, de processos em andamento ou já arquivados, bem como o devido registro de empréstimo desse processo para retirada do DAG. A figura 04 apresenta o fluxo desenvolvido pelos próprios funcionários para a solução deste problema.

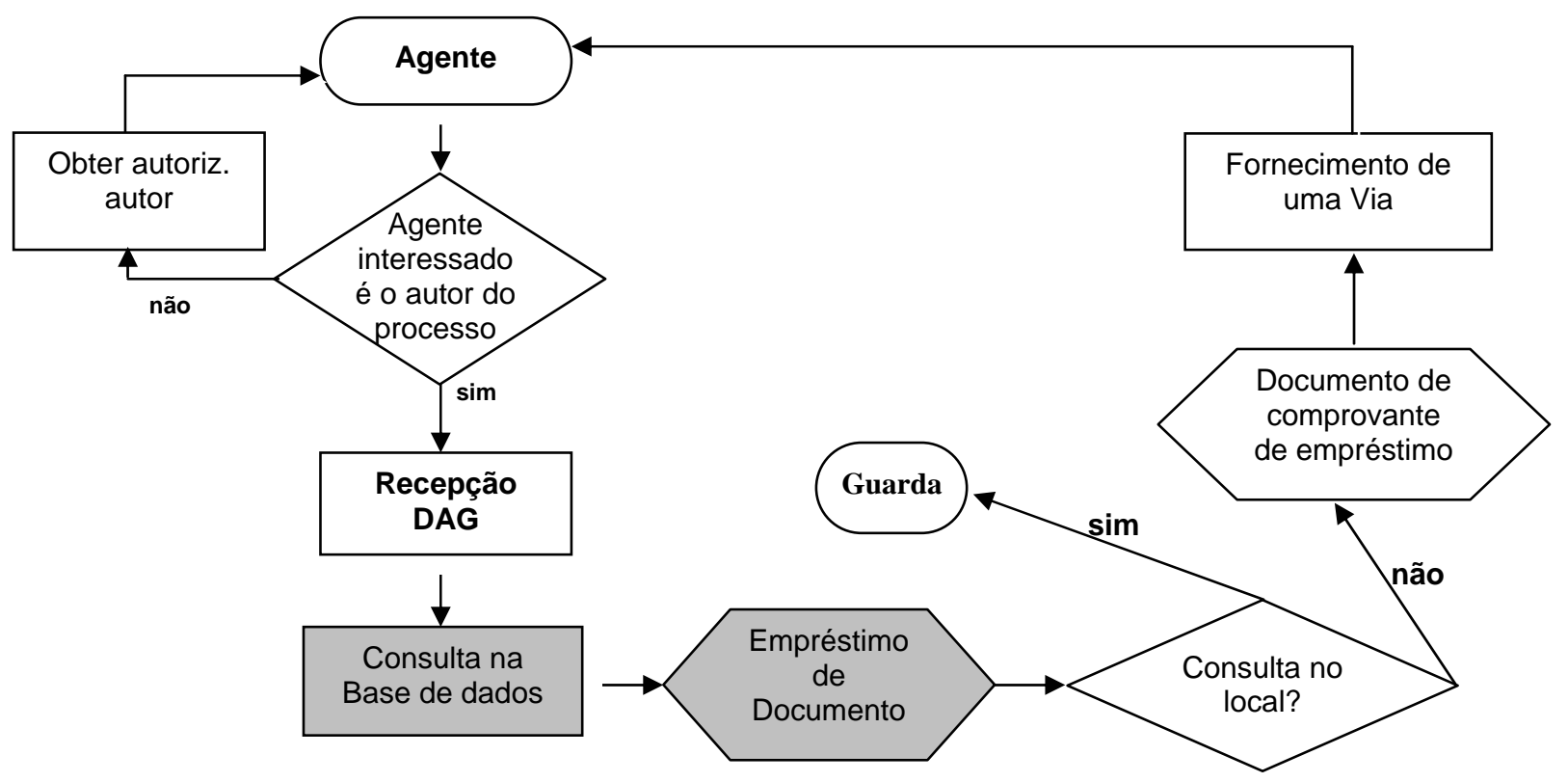

Figura 04: Fluxograma de consulta e empréstimo de processos no MS Access no DAG 
Como pode ser visualizado na figura 04, o agente, quando necessita consultar um processo, precisa ser o autor desse ou, em caso contrário, deve trazer uma autorização por escrito do autor. De posse dos documentos legais, é consultado a base de dados local do DAG, onde os documentos podem ser consultados para sua localização. Da mesma forma, o sistema registra o empréstimo para que esse usuário possa retirá-lo do DAG, estabelecendo um prazo determinado para o seu retorno.

\section{Conclusões}

A Análise Contextual de Tarefa não é uma técnica nova, mas o seu potencial para o desenvolvimento de sistemas de informação deve ser explorado dentro de um contexto mais amplo, que privilegie o diálogo necessário entre usuários e desenvolvedores. Ao estabelecer parâmetros de construção mais próximos ao mundo habitual dos reais utilizadores da aplicação e ao desenvolver uma forma de observação centrada na resolução dos problemas (tarefas) do usuário, a técnica explanada durante o artigo pode auxiliar nas primeiras etapas do desenvolvimento de um sistema de informação, principalmente no que concerne à reorganização das tarefas que, por muitas vezes, é necessária para uma posterior implementação de sistemas automatizados.

Como citado durante todo o trabalho, muitos departamentos não utilizam o módulo que já se encontra implementado, se utilizando de livros-protocolo no seu lugar. Logo, percebe-se a importância do tratamento para a questão cultural quando do envolvimento do usuário que apresenta resistência à inovação, principalmente relacionada à tecnologia. Quando o "novo" é encarado como assustador, transparece o despreparo do órgão e não do usuário. Quando visa modificar seu ambiente, é importantíssimo trabalhar sob o convencimento através de uma argumentação de apresentação de melhorias para o aumento da eficiência através do aumento das facilidades para atividades mais práticas. Não devemos cobrar bons desempenhos de algo, se não foi ensinado a usá-lo.

No entanto, é necessário ressaltar um último aspecto importante. A decisão final para a implementação dos processos informatizados deve ser feita de comum acordo entre os usuários e os desenvolvedores. Essa ressalva é crucial para não incutir o erro de simplesmente passar o poder decisório, antes completamente centrado na Tecnologia da Informação, para o usuário. Nenhuma das duas soluções é satisfatória, se tomada isoladamente. Erros causados por programas mal conduzidos por usuários custam tanto quanto erros que aparecem em centros de desenvolvimento de software tradicionais (Burnett, et al, 2004).

\section{Referências}

AKERS, David L. Observation-based design methods for gestural user interfaces. ACM: Conference on Human Factors in Computing Systems - CHI '07 extended abstracts on Human factors in computing system. USA: San Jose. p. 1625 - 1628, 2007.

BURNETT, Margaret, COOK, Curtis, ROTHERMEL, Gregg. End-user software engineering. Communications of the ACM. v. 47, n. 9. p. 53-58. 2004.

CRUZ, Tadeu. Workflow: a tecnologia que vai revolucionar processos. 2.ed., São Paulo: Atlas, 2000. 
CYBIS, Walter de Abreu. Ergonomia de interfaces homem-computador. Apostila para o curso de Pós-Graduação em Engenharia de Produção - Universidade Federal de Santa Catarina. Florianópolis, 1997.

HOELZEL, Carlos Gustavo Martins. Design ergonômico de interfaces gráficas humano - computador: um modelo de processo. 2004. Tese (Doutorado em Engenharia da Produção). Universidade Federal de Santa Catarina, Florianópolis, 2004.

MAYHEW, Deborah. The usability engeneering lifecycle: a practioner's handbook for user interface design. San Francisco: Morgan Kaufmann Publishers, 1999.

PAULINO, Rita de Cassia Romeiro. Metodologia de Avaliação Centrada no Usuário para a Melhoria Contínua no Processo de Desenvolvimento de Sistemas. Dissertação de Mestrado: Programa de Pós-Graduação em Engenharia da Produção. Universidade Federal de Santa Catarina, 1999.

PRESSMAN, Roger S. Engenharia de Software. São Paulo : McGraw-Hill, 2006.

REZENDE, D. A. Engenharia de Software e Sistemas de Informação, Rio de Janeiro: Brasport, 2005.

SOMMERVILLE, Ian. Engenharia de Software. São Paulo : Addison Wesley, 2003.

WINCKLER, M. Avaliação de Sites Web. In.: Anais...4. Workshop sobre Fatores Humanos em Sistemas Computacionais, IHC 2001, Florianópolis - SC, 15-17 de outubro de 2001. (Mini-curso) 